\title{
Diversity \\ Management: \\ Development, \\ Practices, and \\ Perceptions among \\ State and Local \\ Government Agencies
}

By Heather Wyatt-Nichol, PhD, and Kwame Badu Antwi-Boasiako, PhD

As diversity increases among citizens and employees, human resource practitioners in the public sector have come to view diversity management strategies as essential for the effective performance of organizations. An examination of best practices among private and public organizations reveals common components necessary for successful diversity initiatives. While there have been numerous studies on diversity management in the federal government, far less is known about diversity management at the state and local level. In light of the best practices research on the factors necessary for successful diversity management, this study examines the extent of diversity initiatives at various state and local government agencies. Measures used to develop diversity strategies, diversity management practices, professional development initiatives, organizational policies, and perceptions of effectiveness are considered. The findings demonstrate a few variations based on level of government, region, and size of agency. In addition, the majority of respondents believed that the organization's diversity strategy was effective at recruitment, retention, development, and promotion; however, there was uncertainty about the effectiveness of the diversity strategy on organizational performance. 


\section{Introduction}

The subject of diversity has become salient to employers, as demographics have changed within American society. In 2007, labor force participation rates of women were at $57 \%$, of which $71 \%$ had children less than 18 years of age. ${ }^{1}$ African Americans comprised 11\% of the labor force, Hispanic and Latinos accounted for 14\%, and Asians represented 4\%. ${ }^{2}$ Among the 30.6 million individuals between the ages of 21 and 64 who have a disability, 57 percent were employed. ${ }^{3}$ Although labor force participation among workers typically declines with age, employment among workers over 65 years of age is expected to double, increasing from 3.6\% of the total labor force in 2006 to $6.1 \%$ by $2016 .{ }^{4}$ As employees increasingly represent a wide variety of different backgrounds and preferences, human resource practitioners have come to view diversity management strategies as critical for the effective performance of organizations.

The concept of diversity management is originally attributed to Roosevelt Thomas 5 and most definitions today include some variation of his original definition, which emphasizes inclusiveness and performance (see table 1). The emphasis on inclusiveness expands social identity categories beyond those that are legally protected under Title VII of the Civil Rights Act. Primary dimensions of diversity are factors that are unchangeable (e.g., race, ethnicity, gender, age) and secondary dimensions are described as "malleable factors," which may include marital status, parental status, educational background, socio-economic status, geographic location, and work experience. ${ }^{6} \mathrm{~A}$ similar model by Johnson incorporates organizational dimensions including: work location, functional level-classification, division or department, seniority, management status, and union affiliation. ${ }^{7}$

Workforce diversity has the potential to improve service delivery and performance by way of understanding the values and norms of target populations the organization serves, particularly for public employees in service delivery organizations. Recognizing the importance of diversity, many organizations have developed policies and professional development initiatives to attract, retain, and develop employees, as well as facilitate communication and understanding among employees. Recognizing the various factors that make organizations unique (e.g., purpose, size, structure, location, etc.), diversity management initiatives vary.

There has been a wealth of information on diversity initiatives in the federal government, however, less is known about the state and local levels. This article examines diversity initiatives among a variety of state and local government agencies, particularly organizational policies and professional 
development initiatives in light of previous best practices research on the common components necessary for successful implementation of diversity initiatives.

\section{Diversity Management}

Although diversity management has received considerable attention among human resource professionals, many organizations lack an official definition. According to a recent survey conducted by the Society for Human Resource Management, only 39\% of respondents reported an official definition of diversity within their organization. Among those respondents, 39\% represented public sector organizations compared to the private (26\%) and non-profit sectors (25\%). ${ }^{8}$ Though organizations define diversity differently, Thomas (1992) insists that such differences in interpretation must not prevent the benefits diversity brings to organizations and society as a whole. It should be encouraged and managed properly. He asserts, "Managing diversity simply calls for the manager to ensure that cultural and political realities do not advantage or disadvantage anyone because of irrelevant considerations."

\section{Table 1: Diversity Definitions}

To celebrate diversity is to appreciate and value individual differences. SHRM strives to be the leader in promoting workplace diversity. Although the term is often used to refer to differences based on ethnicity, gender, age, religion, disability, national origin and sexual orientation, diversity encompasses an infinite range of individuals' unique characteristics and experiences, including communication styles, physical characteristics such as height and weight, and speed of learning and comprehension (Society for Human Resource Management www.shrm.org/diversity/library)

\section{Diversity Management Critical Success Factor}

Definition: The agency maintains an environment characterized by inclusiveness of individual differences and responsiveness to the needs of diverse groups of employees (Office of Personnel Management http://www.opm.gov/hcaaf_resource_center/5-7.asp)

Diversity management also emphasizes organizational performance through recruitment, retention, and development strategies beyond the legal framework of Equal Employment Opportunity and Affirmative Action (EEO/AA). Organizations seek to address underrepresentation and maintain compliance with the law through affirmative action plans. In contrast, organizations seek to increase productivity and performance through diversity 
management. ${ }^{10}$ Riccucci refers to managing diversity as "the ability of top management to develop strategies as well as programs and policies to manage and accommodate diversity in their workplaces." 11 Overall, diversity management programs are designed to increase cultural sensitivity, develop awareness and recognition of issues relevant to diversity, reduce inequality among women and minorities, improve communication among various groups within an organization, and revise leadership practices and the culture of an organization. ${ }^{12}$ Common recommendations for diversity initiatives at the federal level include: management accountability, an examination of organizational structure and processes, attention to diversity representation, training and mentoring programs, identification and advocacy of nontraditional groups, and an emphasis on shared values. ${ }^{13}$

\section{Representative Bureaucracy, Cultural Competency, and Organizational Effectiveness}

Proponents of diversity management offer normative claims and theoretical arguments that link diversity to organizational effectiveness. Some might argue that "diversity is a desirable goal in itself" 14 and that democracy requires a representative bureaucracy staffed with employees that reflect the population at large. Others maintain that representative bureaucracy leads to better organizational performance and service delivery. For example, Rice provides compelling arguments to demonstrate the importance of cultural competence within organizations and defines a culturally competent organization as, "one that acknowledges and incorporates - at all levels - the importance of culture, assessment of cross culture relations, vigilance toward the dynamics that result from cultural differences, expansion of cultural knowledge, and adaptation of services to meet culturally unique needs." 15 While the framework of cultural competence extends beyond diversity management, it cannot occur in the absence of diversity. Based upon the premise that service delivery is improved when service providers understand the values and norms of the population served, federal and state organizations within the health and human services industry now require training and the demonstration of cultural competence. ${ }^{16}$

Among the competencies necessary for human resource (HR) professionals, diversity management skills are considered important. Among the important outcomes of diversity management, HR professionals reported that it was important to establish a work environment that values contributions from all members in the organization (96\%), leverage workforce differences for strategic advantage (84\%), and eliminate or minimize prejudice (78\%). ${ }^{17} \mathrm{Sim}$ - 
ilarly, workforce diversity is included as a critical success factor for a "results oriented performance culture"-one of the key elements in the Office of Personnel Management (OPM) Human Capital Assessment and Accountability Framework. ${ }^{18}$

In addition to normative claims and theoretical arguments that support diversity management, a recent study by Pitts provides empirical evidence linking diversity management to organizational performance. Using data from the 2006 Federal Human Capital Survey he found that positive perceptions of work group performance were more prevalent among whites than minorities. An examination of gender differences also revealed that women were more likely to have positive perceptions of group performance. Of greater significance is evidence of a positive relationship between diversity management, job satisfaction, and organizational performance. According to Pitts, "Diversity management is positively and significantly related to job satisfaction, indicating that the most satisfied employees work in units where they report diversity management as being strong." ${ }^{19}$

\section{Best Practices of Diversity Management}

An examination of best practices among private and public organizations reveals common components necessary for successful diversity initiatives. The U.S. Department of Commerce and former Vice President Al Gore's National Performance Review (NPR) benchmarking study on best practices in diversity management identified the following factors as necessary to successfully implement diversity initiatives: leadership commitment, employee participation, strategic planning, indicators, accountability and measurement, and linking diversity efforts to organizational goals and objectives. ${ }^{20}$ Similarly, the Government Accountability Office (GAO) examined best practices at the federal level in 2005 and identified the following 10 agencies (listed in rank order) as demonstrating best practices in diversity management: U.S. Coast Guard, National Institute of Standards and Technology (NIST), Department of Veterans Affairs (VA), Federal Bureau of Prisons (BOP), U.S. Postal Service, National Oceanic and Atmospheric Administration (NOAA), Veterans Health Administration (VHA), Food and Drug Administration (FDA), Federal Aviation Administration (FAA), and National Institutes of Health (NIH). ${ }^{21}$ The leading diversity management practices in the report include: commitment from leadership, linking diversity to the strategic plan, recruitment, succession planning, employee involvement, diversity training, and accountability and measurement. 


\section{Commitment from Leadership}

Leaders and managers are responsible for implementing policy within the organization. They demonstrate commitment to diversity initiatives when they provide resources in the form of funding or personnel and increase the visibility of diversity initiatives through a variety of communication structures within the organization including formal statements of policy, meetings, and newsletters. Leading by example increases the likelihood that supervisors demonstrate an effort to support the diversity initiatives. Briefly stated, "...expression of support must be visible, specific, personal, and persistent." 22 Among the Executive Core Qualifications (ECQ) required for Senior Executive Service in the federal government, leveraging diversity is one of the components included in ECQ2: Leading People. ${ }^{23}$

\section{Part of the Strategic Plan}

According to one GAO report, “.... an organization must link diversity to its overall strategic plan to ensure that diversity initiatives are not viewed as an "extra" which could make them vulnerable to cuts when funds are tight." 24 Among the 120 federal agencies that reported having diversity initiatives in place in 1999, 72\% linked those initiatives to the strategic plan. ${ }^{25}$ The NPR Best Practices report identified several strategies used by organizations to link diversity to the strategic plan, including: tracking workforce characteristics and establishing annual targets and 10 year goals, linking diversity to goals and objectives within the strategic plan, developing action plans, and incorporating diversity into leadership training programs. ${ }^{26}$ The GAO highlighted the Food and Drug Administration as one example of incorporating diversity into the strategic plan. Strategic goals included the eradication of discrimination, promotion of diversity at all levels, and opportunities for participation. ${ }^{27}$

\section{Recruitment}

Federal agencies often reach out to minority colleges and universities in an effort to attract diverse candidates. For example, the National Institute of Standards and Technology has partnered with historically black colleges and universities to provide research and development opportunities. ${ }^{28}$ In addition, as the number of employees eligible for retirement increases among public organizations, the need to recruit mid-career professionals has also received attention. Strategies to attract diverse mid-career employees include speaking engagements and advertising at events sponsored by multicultural professional organizations. OPM also includes recruitment among the diversity management effectiveness indicators: "A recruitment strategy to reach diverse populations at 
colleges/universities, minority-focused professional organizations, and other organizations representing women, veterans, people with disabilities, and other groups as part of the agency's overall outreach strategy." 29

\section{Succession planning}

The number of employees eligible for retirement also highlights the importance of succession planning. To ensure a qualified and diverse pool of executive candidates the Office of Diversity within the U.S. Postal Service announces the succession planning cycle on an annual basis that incorporates individual development plans through a web-based system. ${ }^{30}$ The system allows individuals and the organization to assess employee knowledge, skills, and abilities, and track development to ensure that training and experience meet projected workforce demands.

\section{Employee involvement}

Employee participation is essential to garner support for diversity initiates. Including employees during the formulation phase provides legitimacy and a sense of ownership to the process. Most of the 10 agencies examined by the GAO had some type of employee participation in place, often in the form of diversity task forces and diversity boards, to identify issues and develop initiatives. Similarly, OPM recommends, "surveys and/or interviews to show the workforce is aware of, and generally supports, diversity program efforts" as part of their diversity effectiveness indicators. ${ }^{31}$

\section{Diversity training}

While the content and delivery mechanisms for diversity training may vary, training is necessary to raise awareness and develop the necessary skills to work with diverse employees internally and improve service delivery to citizens externally. The disadvantage of diversity training is that many organizations view it as a one-time event rather than a continuous process. ${ }^{32}$ According to Naff and Kellough, although 85\% of the federal agencies in the diversity task force study required diversity training, only $32 \%$ required "training beyond an initial course." ${ }^{33}$ Caudron also highlights the importance of extending training beyond raising awareness to providing trainees with practical skills to deal with diversity issues. ${ }^{34}$ In addition, training that emphasizes diversity as part of the strategic plan to improve organizational performance is more likely to receive a positive response from employees than training that emphasizes legal compliance to EEO/AA. Therefore, it is imperative that the organization clarifies the distinctions between EEO/AA and diversity management among its employees. ${ }^{35}$ 


\section{Accountability and measurement}

Measurement is useful for developing and sustaining diversity initiatives. Organizations must assess the current environment prior to developing any diversity initiative. OPM recommends cultural audits to assess the cultural environment and identify potential obstacles. ${ }^{36}$ In addition, it is also necessary to collect baseline data in order to track progress over time. Measures might include traditional workforce demographics in areas of recruitment, selection, and promotion, and attrition. For example, the Department of Veterans Affairs uses workforce data to assess diversity in the leadership pipeline. ${ }^{37}$ Measures might also include employee and/or citizen satisfaction surveys, perceptions of organizational support, diversity training attendance, and number of complaints and grievances within a specific timeframe. The National Oceanic and Atmospheric Administration uses a Survey Feedback Action Process (SFA) to measure employee perceptions and assess progress of the diversity strategy. ${ }^{38}$ Balanced scorecard approaches have also been implemented in several organizations. The NPR Best Practices report cites one organization that uses a scorecard approach to include the following indicators: "1) coaching as the tool to build awareness around diversity and continuing the company's goal to mainstream diversity; 2) Workforce representation plan; 3) Employee council activities." 39

Accountability is often achieved through measurement. The role of managers is particularly important since they interact with employees on a daily basis and are responsible for the implementation of diversity strategies. Managers can be held accountable for diversity initiatives by linking performance ratings to the manager's success in achieving diversity goals. For example, a former Commerce Secretary issued a department memo, "requiring that the performance plan for each manager and supervisor include a critical element promoting diversity, assigned a weight of at least 15 percent." 40

\section{Best Practices among State and Local Governments}

The International Public Management Association for Human Resources (IPMA-HR) in cooperation with the National Association of State Personnel Executives has been benchmarking best practices, which includes a component on diversity. Similar to the common components necessary for successful diversity initiatives at the federal level, the IPMA-HR Benchmarking Committee identified common components at the state and local level. The components for successful implementation include: diversity training, linking diversity strategies to organizational performance, accountability through measure- 
ment, and decentralized efforts through a centralized governing body. The states and localities recognized for "diversity/affirmative action" initiatives in the 1998 and 2001 IPM-HR Best Practices Report include: Arizona, Montana, Oklahoma, Washington, Wisconsin, and the City of St. Petersburg, Florida. Many of the states have been recognized for efforts to increase the number of women and minority employees. For example, Arizona was recognized for increasing minority representation from 1997-2002, reflecting the efforts of the joint partnership between the personnel office and the governor's office to recruit a more diverse workforce. ${ }^{41}$ Montana was recognized for increasing the number of female employees from 1981-1998. Under-representation of minorities is considered through agency affirmative action plans and agencies are responsible for addressing barriers. Oklahoma was noted for having higher minority representation among state employees (19.2\%) compared to $16.7 \%$ in the civilian labor force. Similarly, minorities represented $14.9 \%$ of state employees in Wisconsin in 1998 compared to $7.4 \%$ in the civilian labor force. ${ }^{42}$ In contrast, the state of Washington is acknowledged for having a diversity plan that addresses representation of not only women and minorities, but also individuals with disabilities, persons over 40 , and veterans. Because their efforts are inclusive, it extends to $70 \%$ of the workforce and counters negative perceptions of traditional affirmative action programs. ${ }^{43}$ The state of Colorado has also been recognized for its diversity plan, originally established through an executive memo by the governor in 1995. Responsibilities for implementation were placed in the Executive Director's Office. The strategic plan includes goals and objectives on the following diversity components: family friendly workplace, recruitment, community and advisory council partnerships, career development, and employee awareness programs. In addition, assessment of

\section{Table 2: State Definitions Examples}

Diversity, as it relates to the workplace, means the many differences among employees. Employees differ from each other in experience, age, gender, race, national origin, native language, religious preference, cultural heritage, civil status and in many other ways. A diversity policy is a policy which promotes respecting and celebrating our many differences. The goal of a diversity policy is a workplace in which no employee is favored or disfavored because of a non-employment-related trait or feature. Diversity is not a form of affirmative action (Colorado Department of Transportation http://www.dot.state.co.us/EEO/Diversity.htm)

The state of Washington is committed to an inclusive environment where all employees are treated with respect, are valued, and have the opportunity to contribute to their fullest potential...Diversity, equal employment opportunity, and affirmative action are key to creating an inclusive work environment (Washington State Department of Personnel http://www.dop.wa.gov/diversity/Pages/default.aspx) 
each component is required every two years. ${ }^{44}$ Similarly, the governor of Pennsylvania issued an executive order (2008-06) that established an Office of Diversity Management with a Chief Diversity Officer to develop and implement a strategic plan, measure diversity efforts, and "incorporate diversity management best practices into Commonwealth agency policies, practices, structures, goals, and objectives." 45

The 1998 and 2001 IPMA-HR Best Practices Report also recognized the City of St. Petersburg, Florida and the City of Fort Collins, Colorado. The City of St. Petersburg has increased representation of women and minorities throughout its workforce. Managers are also required to attend an eight-week seminar on diversity. The City of Fort Collins has also been recognized by IPMAHR for a diversity plan that emphasizes leadership, service provision, and employment opportunities. The leadership component addresses partnerships within the community, service provision addresses meeting the needs of diverse constituents, and the employment component addresses recruitment and retention strategies.

In light of the best practices research on the factors necessary for successful diversity management, this study explores the extent of diversity initiatives among state and local government agencies. The development of diversity initiatives, practices, policies, and perceptions of effectiveness are considered. Regional comparisons and agency size are also examined.

\section{Methodology}

This study uses a cross-sectional research design to examine diversity initiatives among state and local government agencies. A survey was developed to measure the specific areas of interest. Several items in the online survey were extracted from the telephone survey of the NPR best practices study, specifically: item 2primary responsibility, item 5- incorporation of the diversity strategy, item 9- leadership commitment, and item 10-frequency of measurement.

A sampling frame was developed using the IPMA-HR membership directory. The member directory search provides a variety of search options based on individuals, organizations, and membership categories. The criteria used were "organization" with a membership class of "agency membership" for each state, resulting in a list of 1278 organizations with agency memberships. From this list a purposive sample of 500 human resource professionals representing state and local organizations was selected. The survey was placed online using SurveyMonkey as the host site. An email invitation and follow-up reminders were sent out resulting in a $31 \%$ response rate $(n=153)$. Although an average response rate has not been established for online surveys, the response rate 
for this online survey is similar to that of mail surveys, which typically yield 2040 percent with a follow-up. ${ }^{46}$

\section{Results}

\section{Characteristics}

Among the human resource professionals responding to the survey, 28\% are employed by state government agencies and $72 \%$ are employed by local government agencies. An examination of respondents based upon the U.S. Census Bureau regions ${ }^{47}$ reveals that $9 \%$ work in the Northeast, 32\% in the South, 26\% in the Midwest, and 33\% work in the West. The median size of organizations included in this study is 760 employees.

Respondents were also requested to list the number of full-time employees within the organization. This variable was re-coded to examine agency size and diversity initiatives. Organizations with less than 1,000 employees were assigned a value of 1 to represent smaller organizations and those 1,000 or more employees were assigned a value of 2 to represent larger organizations. Fifty-eight percent of respondents were employed by smaller organizations and $42 \%$ were employed by larger organizations.

Regarding responsibility for managing diversity, Human Resource Departments (73\%) were most frequently, although Civil Rights Departments or Divisions (16\%) and Offices of Diversity (6\%) were also reported. Four percent reported "other". Many organizations also have variations, for example, one respondent stated that the diversity office is housed within the Human Resources department. One respondent noted that the Labor Relations Department was responsible for diversity management. Another respondent wrote, "HR has the primary responsibility of "championing" diversity, but each department has accountability for their efforts and progress." The majority of respondents (66\%) reported that their organization measures its diversity strategy on an annual basis.

Respondents were asked to include the dimensions of diversity that are specifically addressed in their organization's diversity strategy. The majority of organizations included race (97\%), sex (94\%), disability (77\%), age (76\%), and religion (59\%) in their diversity strategies. In comparison, fewer organizations included sexual orientation (43\%) and social class (19\%). One respondent indicated that their organization included transgender as a dimension of diversity. Another respondent stated, "We define diversity with a very broad brush. In addition to those described above, we also include education, gender identity, body size, etc." 


\section{Development of the Diversity Strategy}

The majority of respondents reported the use of workforce demographics (81\%) as a measure to develop the organization's diversity strategy. In comparison, organizations were divided on a number of measures to develop their strategies, including: the proportion of diversity among management positions (49\%), complaints and grievances (48\%), and training attendance (48\%). Many respondents also reported the use of turnover (39\%); however, compensation analysis (20\%) and internal lateral moves (17\%) received less consideration. Although several organizations applied the results of employee satisfaction surveys (28\%), far fewer used citizen satisfaction surveys (10\%). Only $9 \%$ of organizations considered employee utilization of work-life family programs to develop diversity strategies.

A comparison of state and local agencies in Table 3 illustrates that states were more likely to consider employee surveys, workforce demographics, degree of diversity at the management level, and complaints and grievances to develop a diversity strategy for the organization.

\section{Table 3: State and Local Comparisons of Measures Used to Develop Diversity Strategy}

\begin{tabular}{l|c|c}
\hline & State & Local \\
\hline Employee surveys & $37 \%$ & $25 \%$ \\
\hline Citizen surveys & $2 \%$ & $13 \%$ \\
\hline Workforce demographics & $91 \%$ & $76 \%$ \\
\hline Compensation analysis & $23 \%$ & $19 \%$ \\
\hline Turnover & $40 \%$ & $39 \%$ \\
\hline Proportion of diversity among management & $56 \%$ & $47 \%$ \\
\hline Prior diversity training attendance & $44 \%$ & $50 \%$ \\
\hline Work-life/family program utilization & $9 \%$ & $9 \%$ \\
\hline Complaints/Grievances & $58 \%$ & $45 \%$ \\
\hline Internal lateral moves & $14 \%$ & $18 \%$ \\
\hline
\end{tabular}

$\%$ of state and local organizations using specific measures

There were no significant differences between region and the dimensions included in the organization's diversity strategy. As previously noted, most organizations included the dimensions of race, sex, age, disability, and 
religion, while fewer organizations included sexual orientation or social class. Among the regional comparisons of measures used to develop the diversity strategy within the organization, only training attendance was statistically significant $(\mathrm{x} 2=8.44, \mathrm{df}=3, \mathrm{p}<.05)$. Organizations in the West $(58 \%)$ and the South (54\%) were more likely to include training attendance as a measure to develop their diversity strategy than organizations in the Northeast (29\%) and the Midwest (68\%).

An examination of agency size and measures used to develop the diversity strategy reveals statistically significant differences between agency size and the use of workforce demographics $(\mathrm{x} 2=14.97, \mathrm{df}=1, \mathrm{p}<.01)$, consideration of the proportion of diversity among management positions $(\mathrm{x} 2=29.47, \mathrm{df}=1$, $\mathrm{p}<.01)$, and consideration of complaints and grievances $(\mathrm{x} 2=9.13, \mathrm{df}=1$, $\mathrm{p}<.01)$. Larger organizations were more likely to use workforce demographics (95\%), proportion of diversity among management positions (75\%), and complaints and grievances (62\%), to develop their diversity strategies than smaller organizations (69\%, 30\%, and 37\% respectively).

\section{Diversity Management Practices}

Among the diversity management practices within organizations, diversity training (80\%), recruitment efforts (78\%), and top leadership commitment (66\%) were most frequently cited. Many agencies also reported diversity as part of the strategic plan (42\%), employee involvement (39\%), and measurement (38\%) as part of their diversity management practices. Succession planning (21\%) and accountability (12\%) were less likely to be included in the diversity management practices of the organizations represented.

When asked about evidence of leadership commitment to diversity management, 69\% of respondents reported that leaders within their organization demonstrate commitment through managing by example. Respondents were nearly divided on leadership commitment demonstrated through inclusion of diversity topics at meetings ( $46 \%$ yes, $54 \%$ no). In comparison, less than half of the respondents reported evidence of leadership commitment on the following items: mentoring (32\%), involvement in diversity training (33\%), funding (33\%), other dedicated resources (21\%), and recognition of diversity champions (19\%).

The only significant difference between state and local agencies on diversity management practices was accountability through measurement $(\mathrm{x} 2=4.30$, $\mathrm{df}=1, \mathrm{p}<.05$ ). State organizations were more likely to engage in measurement (51\%) than local government organizations (33\%). In contrast, diversity management practices were similar for most respondents regardless of state or local status. For example, the majority of organizations used recruitment and training 
while succession planning and accountability were less likely to be included among the diversity management practices (see table 4).

\section{Table 4: Comparisons of Diversity Management Practices among State and Local Government Agencies}

\begin{tabular}{l|c|c}
\hline & State & Local \\
\hline Top leadership commitment & $67 \%$ & $66 \%$ \\
\hline Diversity is part of the strategic plan & $54 \%$ & $38 \%$ \\
\hline Measurement & $51 \%$ & $33 \%$ \\
\hline Accountability through performance assessment & $19 \%$ & $10 \%$ \\
\hline Succession planning & $23 \%$ & $20 \%$ \\
\hline Recruitment & $84 \%$ & $75 \%$ \\
\hline Employee involvement & $35 \%$ & $40 \%$ \\
\hline Diversity training & $88 \%$ & $77 \%$ \\
\hline
\end{tabular}

Among the diversity management practices across regions, only employee involvement was significant $(\mathrm{x} 2=12.19, \mathrm{df}=3, \mathrm{p}<.01)$. Respondents working in the Midwest reported a greater use of employee involvement (62\%) than those in the Northeast (21\%), South (37\%), and West (29\%). In contrast, the majority of respondents in all regions reported top leadership commitment, recruitment, and diversity training as part of their diversity management practices.

An examination of agency size and diversity management practices reveals significant differences on top leadership commitment, diversity as part of the strategic plan, measurement, recruitment, and diversity training (see table 5). Not surprisingly, larger agencies were more likely to engage in a greater number of diversity management practices. Evidence of leadership commitment was more likely to be demonstrated in larger agencies. Although the majority of leaders in organizations did not exhibit commitment through dedicated resources and funding, larger agencies were more likely to provide dedicated resources beyond funding (29\%) than smaller agencies (12\%) $(\mathrm{x} 2=6.93, \mathrm{df}=1, \mathrm{p}<.01)$. Similarly, larger agencies $(42 \%)$ demonstrated commitment to diversity through funding more frequently than smaller organizations $(25 \%)(\mathrm{x} 2=4.89, \mathrm{df}=1, \mathrm{p}<.05)$. Leaders in larger government agencies were more likely to be personally involved in diversity training (50\%) than leaders in smaller agencies $(21 \%)(\mathrm{x} 2=13.40, \mathrm{df}=1, \mathrm{p}<.01)$. Larger agen- 
cies were also more likely to recognize diversity champions (26\%) than smaller agencies $(13 \%)(\mathrm{x} 2=3.96, \mathrm{df}=1, \mathrm{p}<.05)$. There were no differences in agency size and commitment demonstrated through leadership mentoring or the inclusion of diversity topics at meetings.

\section{Table 5: Comparisons of Diversity Management Practices based on Agency Size}

\begin{tabular}{|c|c|c|c|c|}
\hline & $\begin{array}{c}\text { Less than } \\
1,000 \\
\text { employees }\end{array}$ & $\begin{array}{c}1,000+ \\
\text { employees }\end{array}$ & $\mathrm{X} 2$ & p-value \\
\hline Top leadership commitment & $56 \%$ & $77 \%$ & 7.10 & $.008 *$ \\
\hline $\begin{array}{l}\text { Diversity is part of the } \\
\text { strategic plan }\end{array}$ & $26 \%$ & $60 \%$ & 16.63 & $.000^{*}$ \\
\hline Measurement & $24 \%$ & $55 \%$ & 14.65 & $.000^{*}$ \\
\hline $\begin{array}{l}\text { Accountability through } \\
\text { performance assessment }\end{array}$ & $7 \%$ & $16 \%$ & 3.21 & .073 \\
\hline Succession planning & $13 \%$ & $15 \%$ & 2.03 & .154 \\
\hline Recruitment & $69 \%$ & $89 \%$ & 8.19 & $.017^{*}$ \\
\hline Employee involvement & $31 \%$ & $47 \%$ & 3.82 & .051 \\
\hline Diversity training & $69 \%$ & $95 \%$ & 15.45 & $.000^{*}$ \\
\hline
\end{tabular}

*Significant at .05

\section{Formal Organizational Policies}

When queried on formal organizational policies, $76 \%$ of respondents reported a formal policy on diversity training and $66 \%$ reported a policy on diversity measurement. In contrast, only $30 \%$ reported a formal organizational policy to link diversity to the strategic plan. The degree to which the diversity strategy is incorporated into the organization's core values, the strategic plan, its performance indicators, and succession planning efforts also varies. The majority of respondents reported that the diversity strategy is incorporated into core values (58\%) and several incorporate the diversity strategy into the strategic plan (44\%). However, far fewer of the respondents reported strategies within their organizations that incorporate performance indicators (21\%) and succession planning (21\%).

Most organizational policies were similar among state and local organizations. Seventy-four percent of respondents working in state agencies and $62 \%$ of local agencies reported a formal policy on diversity measurement. 
Similarly, formal policies on diversity training were evident in the majority of state $(74 \%)$ and local (77\%) organizations. There was a statistically significant difference between state and local organizations with respect to a formal policy linking diversity to the strategic plan $(\mathrm{x} 2=8.17, \mathrm{df}=1, \mathrm{p}<.01)$. Forty-six percent of respondents working in state organization reported a formal organizational policy linking diversity to the strategic plan compared to only $23 \%$ of local organizations-in part, a reflection of the inclusion of diversity in the strategic plan among state organizations (54\%) compared to local organizations (38\%).

Regional comparisons of organizational policies reveal significant differences between region and a formal policy on diversity measurement $(\mathrm{x} 2=10.04, \mathrm{df}=3, \mathrm{p}<.05)$. Organizations in the Northeast were more likely to have a formal policy on diversity measurement (92\%) compared to organizations in the South (52\%), Midwest (76\%), and West (63\%). Regardless of region, the majority of organizations reported a formal policy on diversity training.

Worker friendly policies that provide flexibility and support were also examined. In the area of flexible hours and location $64 \%$ of respondents indicate that their organizations offered flex-time, however only $37 \%$ reported the use of telecommuting. All organizations offered health care benefits, yet only 35\% extended those benefits to domestic partners. Among the policies that benefit working parents, only 20\% offered paid parental leave beyond FMLA, and very few offered daycare subsidies (4\%) and on-site child care (8\%).

There were no statistically significant differences between state and local government agencies on worker friendly policies. Both were similar in the types of worker friendly policies offered (e.g., health benefits) and not offered (e.g., paid parental leave beyond FMLA) in the organization. Not surprisingly, health care was offered by all state and local organizations. Similarly, $70 \%$ of respondents working in state agencies and 63\% in local government agencies offer flextime. Many state and local organizations also offer telecommuting ( $49 \%$ and $33 \%$ respectively). It is also worth noting that $35 \%$ of state and local organizations provided benefits to domestic partners. While this is well below the majority, it hints at the increasing trend to extend benefits. In contrast, very few organizations had policies in place to provide parents assistance with childcare. Only $5 \%$ of state agencies and $4 \%$ of local agencies provided day care subsidies and only $12 \%$ of state agencies and $7 \%$ of local government agencies offered on-site childcare.

Significant differences across regions were evident for telecommuting $(\mathrm{x} 2=8.63, \mathrm{df}=3, \mathrm{p}<.05)$ and domestic partner benefits $(\mathrm{x} 2=53.53, \mathrm{df}=3$, $\mathrm{p}<.01)$. Organizations in the West were more likely to offer telecommuting 
(51\%) than organizations in the Northeast (14\%), South (29\%), and Midwest (37\%). With respect to domestic partner benefits, 35\% of the organizations in the Northeast (71\%) and the West (67\%) were more likely to extend benefits than organizations in the South (13\%) and the Midwest (8\%). There were no differences among regions on paid parental leave beyond FMLA, on-site childcare, and day care subsidies_-very few organizations offered such benefits.

Not surprisingly, a comparison of agency size and formal organizational policies provides evidence that larger agencies are more likely to have a formal policy on diversity measurement $(78 \%)(x 2=8.39, \mathrm{df}=1, \mathrm{p}<.05)$. Similarly, larger agencies are more likely to link diversity to the strategic plan than smaller agencies ( $48 \%$ and $16 \%$ respectively) $(\mathrm{x} 2=17.0, \mathrm{df}=1, \mathrm{p}<.01)$. On the other hand, there were no differences in agency size and formal policies on diversity training; the majority of agencies had established policies on diversity training.

With respect to family friendly policies, it appears that larger organizations are more likely to offer flextime (76\%) than smaller organizations (55\%) $(\mathrm{x} 2=6.54, \mathrm{df}=1, \mathrm{p}<.05)$. Surprisingly, smaller organizations were more likely to offer paid parental leave beyond FMLA (27\%) than larger organizations $(10 \%)(\mathrm{x} 2=6.84, \mathrm{df}=1, \mathrm{p}<.01)$. There were no significant differences between agency size and day-care subsidies and on-site childcare.

\section{Professional Development Initiatives}

Among the professional development initiatives offered by organizations, 78\% provided tuition re-imbursement, $62 \%$ provided cross-training, and $58 \%$ provided professional development courses within the organization. Less than half of the organizations (34\%) provided a mentoring program. One respondent stated that their organization was developing a "big brother/big sister" mentoring program for professional development within the organization. Another reported a statewide standard for supervisory training.

State and local government agencies were similar in most of the professional development initiatives. The majority of respondents working for state government (56\%) and local government (59\%) reported the use of courses offered within the organization. Similarly, cross-training was offered by $58 \%$ of state government agencies and 64\% of local government agencies. Only $44 \%$ of state agencies and 30\% of local government agencies reported the use of mentoring programs. The only statistically significant difference on professional development initiatives offered by state and local agencies was tuition reimbursement $(\mathrm{x} 2=5.40, \mathrm{df}=1, \mathrm{p}<.05)$. Surprisingly, respondents working for local government were more likely to offer tuition reimbursement (83\%) 
than those working at the state level (65\%). There were no significant differences across regions

There were significant differences based on agency size and the professional development initiatives of mentoring and courses offered within the organization. Respondents working in organizations with more than 1,000 employees were more likely to have a mentoring program (44\%) than smaller organizations $(25 \%)(\mathrm{x} 2=5.47, \mathrm{df}=1, \mathrm{p}<.01)$. Larger organizations were also more likely to offer professional development courses (69\%) than smaller organizations $(48 \%)(\mathrm{x} 2=6.56, \mathrm{df}=1, \mathrm{p}<.01)$.

\section{Perceptions of Effectiveness}

Although most respondents believed that the organization's diversity strategy was effective at recruitment, retention, development and promotion, there was a high degree of uncertainty about the effectiveness of the diversity strategy on organizational performance (see table 6).

\section{Table 6: Perception of Effectiveness of Diversity Strategy}

\begin{tabular}{l|c|c|c|c}
\hline & Recruitment & Retention & $\begin{array}{c}\text { Development \& } \\
\text { Promotion }\end{array}$ & $\begin{array}{c}\text { Organizational } \\
\text { Performance }\end{array}$ \\
\hline Yes & $59 \%$ & $59 \%$ & $52 \%$ & $29 \%$ \\
\hline No & $17 \%$ & $15 \%$ & $19 \%$ & $15 \%$ \\
\hline Uncertain & $24 \%$ & $26 \%$ & $29 \%$ & $56 \%$ \\
\hline
\end{tabular}

The majority of respondents working in state agencies (61\%) and local agencies (59\%) believed that their organization's diversity strategy was effective at recruiting diverse employees. Similarly, 67\% of state agencies and 57\% of local agencies reported that their diversity strategies were effective at retention. In comparison, slightly over half of respondents in state agencies (51\%) and local agencies (52\%) held the perception that strategies within their organizations were effective at promoting diverse employees. There was less certainty among respondents at the state level (54\% uncertain) and local level (57\%) on whether the diversity strategy was effective in improving organizational performance. There were no significant differences in perceptions of effectiveness based on regional differences and agency size.

\section{Perceptions of Future Issues}

Respondents were also asked to provide written comments about their perceptions of the most important issue related to managing diversity in the next ten 
years. Of the 153 respondents, 94 provided written comments. The following themes emerged: recruitment, budgetary constraints, immigration, generational differences, and succession planning. Twenty-one respondents stated that recruitment will continue to be an important concern with respect to managing diversity. Seventeen respondents provided statements that reveal concerns over budgetary constraints. There was specific concern over resources for compensation and recruitment, and "the ability to maintain a competitive salary compared to other municipalities." Others cited the need to balance diversity with reduction-in-force requirements and the need to develop diverse talent within the organization as budget reductions occur throughout the state. Eleven respondents identified growth in the Hispanic population as the most important issue in the next ten years. However, one respondent expressed concern that immigrants will be unavailable to work due to "federal restrictions and verification requirements." An equal number of respondents noted the need to address generational differences, particularly the "different values across the four generations", the need for various age groups to work together, and "making public service attractive as an employment choice to that population."Nine respondents stated that succession planning will be the most important issue in diversity management in the next ten years, specifically "Finding talent to replace baby boomers who will be retiring in the next several years." A few respondents provided comments that did not fit within the common themes identified. For example, one respondent indicated that demonstrated commitment from elected officials as a salient issue in the next ten years. Another respondent highlighted the need to address issues relevant to the Gay, Lesbian, Bi-sexual, Transgender (GLBT) community. One respondent noted the importance of addressing micro-aggression.

\section{Discussion}

Most organizations in this study used workforce demographics to develop a diversity strategy while organizations were nearly evenly divided on the use of training and attendance, complaints and grievances, and the proportion of diversity among management. Even less attention was given to employee surveys when developing the organization's diversity strategy. While state and local agencies are often confronted with unique challenges, consideration should be provided to increasing efforts to elicit employee input and participation because it provides legitimacy, ownership, and increases support for diversity management initiatives.

Measurement and accountability ensure that diversity initiatives are given serious consideration by those responsible for implementation. Slightly over 
half of the state agencies included measurement in their diversity management practices compared to a small percentage of local agencies. Only a small minority of state and local organizations held employees accountable by linking performance assessment and compensation to diversity initiatives. Consideration should be given to developing diversity management measures of performance and incorporating those measures into performance appraisal systems.

Only a small minority of the organizations included succession planning in their diversity management practices, however, most organizations provided tuition assistance, professional development courses within the organization, and cross-training. Surprisingly, respondents working for local government agencies were more likely to provide tuition assistance than state agencies. This could be a reflection of the major budget cuts at the state level during that were only beginning to affect localities at the time the survey was administered. Respondents also identified succession planning as one of the most important issues relevant to diversity management in the next ten years. Overall, it appears that organizations need to coordinate their workforce planning and succession planning efforts with their diversity management practices.

A large majority of the organizations had formal policies on diversity training and included diversity training in their strategic plan. While diversity training is essential to raise awareness and provide skills to improve organizational communication and performance, training itself will be unsuccessful if diversity is not valued within the organizational culture. Less than half of the respondents in this study reported that leaders and senior managers demonstrated commitment to diversity through personal involvement in training. However, a closer inspection of agency size reveals that leaders within larger organizations are more likely to demonstrate commitment in a variety of ways, including personal involvement in training. The limited resources in terms of human capital and funding in smaller agencies may hinder the ability of leaders to exhibit commitment to diversity. Nevertheless, evidence of commitment is illustrated in the fact that there were no differences based on agency size and managing by example - the majority of respondents reported that their leaders demonstrated commitment to diversity through management by example.

Family friendly policies are often included as a diversity management tool because such policies often level the playing field for working mothers. However, few organizations in this study offered paid parental leave beyond FMLA. Organizations were also reluctant to provide assistance to parents in meeting their childcare needs. In fact, the state and local government agencies represented in this study were more likely to provide domestic partner benefits (35\%) than subsidies for day care (4\%) and on-site child care (8\%). 
Overall, the majority of respondents reported that their diversity strategy was effective in terms of recruitment, retention, development, and promotion. Far fewer shared those sentiments when it came to perceptions of organizational performance. In fact, the majority of respondents were uncertain about the effectiveness of their diversity strategy on organizational performance. This uncertainty could be due to ambiguity over what the diversity plan is supposed to accomplish in terms of productivity.

\section{Conclusion}

This study sought to examine the extent of diversity management initiatives among various state and local government organizations and the degree to which state and local organizations demonstrate best practices in diversity management. The results should be interpreted conservatively as the response rate may limit the ability to generalize the findings. Nevertheless, the results provide some insight into diversity management practices among state and local organizations from the perspective of human resource practitioners. This study demonstrates that diversity management should be approached as an integrated and continuous process, tailored to the needs of the organization as variations in capacity and resources exist.

The need to increase awareness among state and local organizations on best practices in diversity management remains salient.

\section{Notes}

1 U.S. Department of Labor, Bureau of Labor Statistics. (2008). Women in the labor force: A databook. Retrieved January 26, 2009 from: http://www.bls.gov/cps/wlfdatabook-2008.pdf

2 U.S. Department of Labor, Bureau of Labor Statistics. (2006). Charting the U.S. labor market in 2006. Retrieved October 9, 2007 from: http://www.bls.gov/cps/labor2006/home.htm.

3 U.S. Census Bureau. (2002). 12 th Anniversary of Americans with Disabilities Act. Retrieved June 15, 2008 from: http://www.census.gov/Press-Release/www/releases/ archives/facts_for_features_special_editions000802.html

4 U.S. Department of Labor, Bureau of Labor Statistics (2008). Older workers. Retrieved August 1, 2008 from: http://www.bls.gov/spotlight/2008/older_workers/

5 Thomas, R.R. (1991). Beyond race and gender. New York: American Management Association.

6 Riccucci, N. (2002). Managing diversity in public sector workforces. Boulder: Westview Press. 
7 Johnson, J.P. III (2003, August). Creating a diverse workforce. SHRM White Paper. Retrieved January 17, 2009 from:

http://www.shrm.org/hrresources/whitepapers_published/CMS_005379.asp

8 Society for Human Resource Management (2008, February). 2007 State of the workplace diversity management. SHRM Research Department, Alexandria, Virginia.

9 Thomas, R.R. (1992). The concept of managing diversity. The Bureaucrat 20:4, 22.

10 Thomas, R. R. (1991), op cit.

${ }^{11}$ Riccucci, N. (2002), op cit., 3

12 Soni, V. (2000) A twenty-first-century reception for diversity in the public sector: A case study. Public Administration Review, 60(5), 395-408.

13 Kellough, J.E. \& Naff, K.C. (2004). Responding to a wake-up call: An examination of federal agency diversity management programs. Administration \& Society, 36(1), $62-90$.

14 Soni, V. (2000), op cit. 395

15 Rice, Mitchell. 2007. Promoting cultural competency in public administration and public service delivery: Utilizing self-assessment tools and performance measures. Journal of Public Affairs Education, 13(1): 41-57. (p. 43).

${ }^{16}$ Wyatt-Nichol, H. \& Antwi-Boasiako, K. (2008). Diversity across the curriculum: Perceptions and practices. Journal of Public Affairs Education 14 (1), 79-90.

17 Society for Human Resource Management (2008, February), op cit.

${ }^{18}$ U.S. Government Accountability Office (2005, January). Diversity management: Expert identified leading practices and agency examples. GAO-05-90, 6

19 Pitts, D. (2009). Diversity management, job satisfaction, and performance: Evidence from U.S. Federal agencies. Public Administration Review, 69 (2), 328-338 (p. 335)

${ }^{20}$ U.S. Department of Commerce and Vice President Al Gore's National Partnership for Reinventing Government Benchmarking Study (1999). Best practices in achieving workforce diversity. Retrieved June 7, 2008 from: http://govinfo.library.unt.edu/ npr/initiati/ benchmk/workforce-diversity.pdf

${ }^{21}$ U.S. Government Accountability Office (2005, January), op cit.

22 Society for Human Resource Management (2008, February), op cit., 22

23 U.S. Office of Personnel Management. Executive core qualifications. Retrieved January 15, 2009 from: http://www.opm.gov/ses/recruitment/ecq.asp

${ }^{24}$ U.S. Government Accountability Office (2005, January), op cit., 10

25 Naff, K.C. \& Kellough, J.E. (2001, December), op cit., 13

${ }^{26}$ U.S. Department of Commerce and Vice President Al Gore's National Partnership for Reinventing Government Benchmarking Study (1999), op cit

27 U.S. Government Accountability Office (2005, January), op cit.

${ }^{28}$ U.S. Government Accountability Office (2005, January), op cit. 
${ }^{29}$ U.S. Office of Personnel Management.(2005, September). OPM/HCAAF diversity definition and performance indicators. Retrieved January 15, 2009 from: http://www.opm.gov/hcaaf_resource_center/assets/Ropc_dm_kepi.pdf

${ }^{30}$ U.S. Government Accountability Office (2005, January), op cit.

${ }^{31}$ U.S. Office of Personnel Management. (2005, September), op cit.

32 Soni, V. (2000), op cit.

33 Naff, K.C. \& Kellough, J.E. (2001, December), op cit. p. 15

${ }^{34}$ Caudron, S. (1993). Training can damage diversity efforts. Personnel Journal, 72, 50-59.

35 Smith, A. (2008). Customize diversity training to meet specific needs. SHRM HR News. Retrieved January 15, 2009 from: http://www.shrm.org/hrnews_published/ARCHIVES/ CMS_025550.asp

${ }^{36}$ Riccucci, N. (2002), op cit.

37 U.S. Government Accountability Office (2005, January), op cit.

${ }^{38}$ U.S. Government Accountability Office (2005, January), op cit.

${ }^{39}$ U.S. Department of Commerce and Vice President Al Gore's National Partnership for Reinventing Government Benchmarking Study (1999), op cit

${ }^{40}$ Naff, K.C. \& Kellough, J.E. (2001, December), op cit., 21

${ }^{41}$ IPMA/NASPE HR Benchmarking project: Best practices (2001/2002 report). Retrieved June 7, 2008 from: http://www.ipma-hr.org/files/2002_01_bp_final.pdf. Now available for purchase at: http://www.ipma-hr.org/hr-resources/hr-solutions/benchmarking-andbest-practices/archived-benchmarking-materials

42 IPMA/NASPE HR Benchmarking project: Best practices (1998 report). Retrieved June 7 , 2008 from: http://www.ipma-hr.org/content.cfm?pageid=294. Now available for purchase at: http://www.ipma-hr.org/hr-resources/hr-solutions/benchmarking-and-bestpractices/1998-best-practices-report\# diversity

43 IPMA/NASPE HR Benchmarking project: Best practices (2001/2002 report), op. cit.

${ }^{44}$ IPMA-HR (2006, February). Personnel practices: Diversity in the workplace policies. Retrieved June 7, 2008 from: http://www.ipma-hr.org

45 Commonwealth of Pennsylvania, Governor's Office. Executive order 2008-06. Retrieved January 29 from: http://www.pabulletin.com/secure/data/vol38/3842/38_42_gov.pdf

${ }^{46}$ Frankfort-Nachmias, C. \& Nachmias, D. (2000). Research methods in the social sciences $\left(6^{\text {th }} \mathrm{ed}\right)$. New York: Worth Publishers.

47 The Census Bureau includes the following states in the Northeast: CT, ME, MA, NH, NJ, NY, PA, RI, VT. The Southern region includes: AL, AR, DE, DC FL, GA, KY, LA, MD, MS, NC, OK, SC, TN, TX, VA, \& WV. The Midwest includes: IL, IN, IO, KS, MI, MN, MO, NE, ND, OH, SD, \& WI. The Western Region includes: AK, AZ, CA, CO, HI, ID, MN, NV, NM, OR, UT, WA, \& WY. 


\section{Authors}

\section{Heather Wyatt-Nichol, PhD}

University of Baltimore

School of Public Affairs

1420 N. Charles St. (LAPB, 434)

Baltimore, MD. 21201

(410) 837-6173

hwyatt-nichol@ubalt.edu

\section{Kwame Badu Antwi-Boasiako, PhD}

Stephen F. Austin State University

Department of Government

Liberal Arts North, \#124

Box 13045, SFA Station

Nacogdoches, TX. 75962

(936) 468-2145

antwibokb@sfasu.edu

Heather Wyatt-Nichol, PhD, is the MPA program director and an assistant professor in the College of Public Affairs at the University of Baltimore in Maryland, where she teaches Diversity Management, Public Personnel, and Public Organizations. Her research interests include diversity management, ethics, family friendly-workplace policies, organizational behavior, and social equity.

Kwame Badu Antwi-Boasiako, $\mathbf{P h D}$, is an interim chair of the Department of Government and associate professor in the MPA program at Stephen F. Austin State University in Texas, where he teaches Public Policy, Program Evaluation, Research Methods, and American Government. His primary fields of interest include traditional institution and democracy in Africa, decentralization, teaching Public Administration, and diversity in the public sector. 